\section{History of High Vacuum and Critical Point Equipment used in EM Specimen Preparation}

Richard A. Denton, Denton Vacuum Inc. Part 1

The electron microscope was only possible with the development of high vacuum technology. Mechanical pumps were available early in this century, and Gaede in Germany developed the mercury pump called a "condensation pump" during WWI and in the 1920's. In 1928, Burch in England found that a low vapor pressure oil would work in a mercury pump and the oil diffusion pump was born. They were made by DPI in Rochester, Metropolitan Vickers in England, and Leybold in Germany. Other oils became available and in the mid-30's, vacuum evaporators were in laboratory use in England, Germany and the United States.

In the 1930's and $40^{\prime}$ 's, the aim was to produce vacuum of $10^{-4}-10^{-5}$ $\mathrm{mm} \mathrm{Hg}$ where the mean free path was two feet or more and atoms, molecules and electrons could move this distance with little obstruction. In those days, we were all very happy to get $10^{-4}-10^{-5}$ without worrying much as to what gas was left.

Back then, main interest then was in what wasn't there. Now, with all the new technology, we no longer worry so much about what isn't there, but what is left there - at any level of pressure down to ultra-high vacuum. So, all elements necessary to pump electron microscopes and evaporators were in place in the 30's, including various electrical vacuum gauges.

RCA developed the first commercial evaporator for electron microscopy. The RCA group was headed by Dr. Bob Picard. The evaporator was called the EMV-5.

The first EM use of vacuum evaporators was for shadow casting. This technique was discovered twice: once in 1942 in Germany by von H.O. Muller and then in 1944 by Robley C. Williams and Ralph W.G. Wycoff at the University of Michigan. Neither group knew what the other was doing because of wartime secrecy.

Robley Willaims, a true innovator, built an evaporator at Cornell in the early 30 s to aluminize telescope mirrors and was so impressed by the technique that he and Joel Ufford started Evaporated Metal Films to metallize front surface mirrors. The company is still in business today. Robley then moved to the University of Michigan where he and Wycoff did the first shadow casting in the United States.

Despite the newer pumps, the majority of shadow casters still use oil sealed mechanical and oil diffusion pumps because of cost versa performance. The original papers on shadow casting by Williams and Wycoff (as well as Muller) are titled "The Thickness of Electron Microscope Specimens." With shadow casting, it became obvious that a much greater contrast was possible.

An interesting sidelight of the RCA original microscope and the EMV5 shadow casting system is that a two-stage fractionating pump, developed by Louis Malter at the RCA Sarnoff Labs in Princeton, NJ, was often used. $\mathrm{DPI}$ of Rochester, NY were the only people in this country selling diffusion pumps. They were going to sue RCA because of their diffusion pump patents, most of which were due to the famous K.D.C. Hickman.

After the fuss, it was determined that Malter's 1937 patent was earlier than DPI's and DPI had to pay license fees until the patent expired in 1954. Malter later became the head of the Varian Vacuum Division.

Optical Film Engineering was started by myself and Tom Scatchard in late 1945 after we had operated a number of evaporators for lens coating at the Frankford Arsenal. We built an evaporator and began coating camera and binocular lenses in December, 1945. Frank Hamm, an electron microscopist, had bought some evaporator components and needed us to make the rest and complete an operational evaporator for electron microscopy work. This was the first vacuum system we sold.

The 1947 EMSA meeting at the Franklin Institute in Philadelphia was about a five minute walk from our shop. There we met Robley Williams and other microscopists and showed pictures of our first evaporator. Harvey Merrill, a RCA salesman at the time, later advised that RCA had stopped making EMV- 5 evaporators after discovering a $\$ 1500$ costing error.
He showed us a copy of an order for an EMV-5 and asked us if we could fulfill it. We cheerfully agreed and delivered an evaporator with an 18" diameter pyrex bell jar - the same size as RCA's.

By 1948 , several enterprising microscopists had made $12^{\prime \prime} \times 12^{\prime \prime}$ bell jar units and we decided that this was the logical size for electron microscopy. And our SC-3 was born (see following Figure).

\section{SC-3 EM EVAPORATOR, 1948}

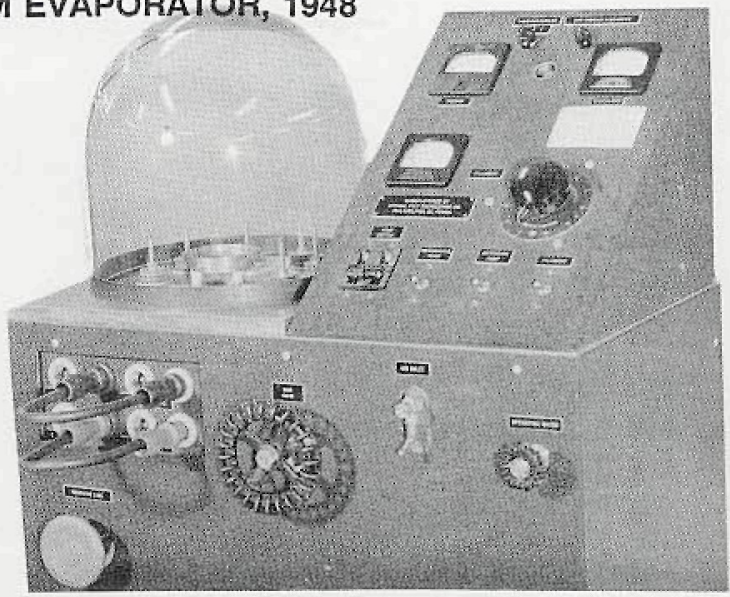

As we could not buy an adequate $3^{\prime \prime}$ diameter diffusion pump for our shadow caster, we we designed and built our own. It worked out very well

I took pictures of the new unit and went to the 1948 Toronto EMSA meeting. I recall riding back in the train with Carl Willoughby and Frank Hamm very disappointed that no one had ordered anything. At that time there were no formal exhibits so all I could do was walk around and talk to anyone who was willing to look at my picture and take my literature. How times have changed!

Happily, shortly thereafter, I received a call from John Watson at the Henry Ford Hospital. Due to my pitch at Toronto, he bought our first SC-3.

The next technique for vacuum evaporators was carbon evaporation. This was introduced by D.E. Bradley in England in 1954. His equipment used two $1 / 4^{\prime \prime}$ carbons, pointed by pencil sharpening, which were spring loaded and included opal and transparent glass plates for judging thickness.

The first commercial carbon evaporator was made by Ernest Fullam using Bradley's system (see following Figure). Seeing this in operation concerned me as the pointed carbons could slide by each other and draw too much current, so I designed one with $1 / 8$ " diameter flat-ended carbon facing another with about $3 / 16$ " turned down to 0.040 " diameter.

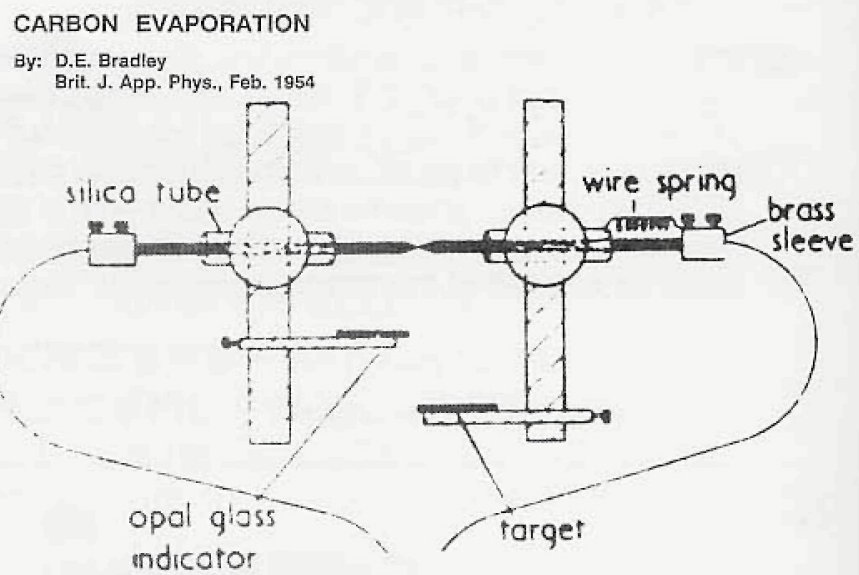

Apparatus for the evaporation of carbon

Our 1954 carbon evaporator included a hand tool for sharpening the carbon section. We had to use carbide tool bits as graphite wrecked regular tools. Many variations have been made including a little lathe by Ladd to turn down the carbons. Our system and Fullam's are is still used today although other methods such as heating carbon cloth or carbon fiber are now used. Many other systems have been devised to metal and carbon coat specimens. 